\title{
A nurse-run program for congestive heart failure reduced time to hospital readmission
}

Cline CM, Israelsson BY, Willenheimer RB. Broms K, Erhardt LR. Cost effective management programme for heartfailure reduces hospitalisation. Heart. 1998 Now;80:442-6.

\section{Question}

Can a nurse-run management program reduce hospitalization and health care costs 1 year after admission for congestwe heart fallure $(\mathrm{CHF})$ ?

\section{Design}

Randomized, unblinded, controlled trial with 1-year follow-up.

\section{Setting}

A wiversity hospital in Malmö, Sweden.

\section{Patients}

206 patients aged 65 to 84 years (mean age $76 y$ y $53 \%$ men; $62 \%$ with moderately severe CHF, New York Heart Association functional class III) who were hospitalized for CHF Exclusion criteria included other serious disease. Follow-3p was $92 \%$.

\section{Intervention}

96 patients were allocated to the intervention group. These patients and their families received nursing education on CHF, encouragement to adhere to medical treatment, and self-management guidelines during hospitalization and 2 weeks after discharge; had follow-up visits at an accessible, nurse-run outpatient clinic; and had outpatient visits with physicians at 1 and 4 month after discharge. 110 patients were allocated to receive routine dinical care (control group).

\section{Main outcome measures}

Number of hospitalizations and readmissions, time to readmission, length of hospital stay, health care costs, mortality, and self-reported quality oflife 1 year after hospitalization for CHF.

\section{Main results}

16 patients in the intervention group withheld consent after randomization; analysis was thus based on 80 patients in the intervention group and $110 \mathrm{pa}-$ tients in the control group. At 1 year, patients in the intervention group had a longer mean time to readmission (141 vs $106 \mathrm{~d}, P<0.05$ ) and trends toward fewer hospitalizations per patient (0.7 vs $1.1, P=0.08$ ) and readmissions (39\% vs $54 \%, P=0.08$ ), a shorter length of hospital stay (4.2 vs $8.2 \mathrm{~d}, P=0.07$ ) and lower mean annual heal th care costs (U.S. $\$ 2294$ vs $\$ 3594 /$ patient, $P=0.07$ ) than those in the control group. $\mathrm{Pa}$ tients in the intervention and control groups did not differ in the 1-year mortality ate $\left(30 \%\right.$ vs $\left.28 \%,\{P=0.8\}^{*}\right)$ or for quality of life assessed by a CHF questionnaire, the Nottingham Heal th Profile, and the global self-assessment questionnaire

\section{Conclusion}

For patients discharged after hospitalization for congestive heart failure, a nurse-run management program reduced the time to readmission but had no effect on the 1 -year mortality rate or quality of life.

Sources of funding: Swedish Heat and Lang Foundation; Malmö University Hospital. Land Universits.

For" conrespondence: Dr: C.M. Cline, Department of Cardiology, Malwo Uniwersity Hospital, Land University, S-205 02 Mahmö, Sweden. FAX 46-40-33-6209.

*P value calculated from data in article.

Abstract and Commentary also published in ACP Fotrnal Chub. 1999;130:81.

\section{Commentary (continued from page 94)}

thus, additional "booster" interventions may be useful in future evaluations.

Because of the lower number of hospital izations in the intervention group, economic evaluation showed a trend toward a mean annual reduction of overall costs of U.S. \$1300 per patient. However, because the mean cost for Swedish hospitalization was U.S. $\$ 381 /$ day, the study likely underestimated the cost benefits in such venues as the United States.

This program may have achieved these benefits by delaying the progression of CHE. When compared with the year preceding the intervention, the number of hospital days in the study group remained stable, whereas that in the control group increased. Although greater use of angiom tensin-converting enzyme (ACE) inhibitors in the intervention group than in the contol group may have contributed to this effect (4), it is unlikely because treatment was started at various times during the follow-up year and treatment differences were small.

Despite the value of improved arug treatments, such as ACE inhibitors and statins, clinical practice must include much more than prescribing drugs. Providers must do more to increase patient knowledge and understanding to improve outcomes in these chronic cardiac conditions (5). Close and continuing follow-up is needed, and this is perkaps best done by skilled nursing staff, as in these studies.

Zeffrey $K$. Mills, $M D, M S C$ University of Toronto

Toronto, Ontario, Canada

References

1. Gotto AM Jr. Giolesterol managenent in theory and practice. Circulation. 1997; $96: 4424-30$.
2. Scandinavian Simvastatin Survival Study Group. Randomised trial of cholesterol lowering in 4444 patients with coromary heart disease: the Scandinavian Simvastatin Survival Study (4S). Lancet. 1994;344: 1383-9.

3. Cupples ME, McKnight A. Randomised controlled trial of health promotion in general practice for patients at high cardiovascular risk. BM]. 1994;309:993-6.

4. Garg R, Yusuf S. Overview of randomized trials of angiotensin-converting enzyme inhibitors on mortality and morbidity in patients with heart failure. Collaborative Group on ACE Enlibitor Trials. JAMA. 1995;273: $1450-6$.

5. Eraker SA, Kirscht JP, Becker MH. Understanding and improving patient compliance. Ann Intern Med. 1984;100:258-68. 